\title{
A CASE OF CONJOINED TWINS (Thoracopagus)
}

\author{
Lieutenant-Colonel B. GAVOURIN, M.B., F.R.C.S.(Glas.), F.R.C.O.G., R.A.M.C.* \\ Lieutenant-Colonel W. H. LEVIS, M.D., D.M.R.D., C.R.C.P.(C), C.F.M.S.
}

British Military Hospital, Iserlohn

\section{Introduction}

In Munro Kerr's classical textbook of Operative Obstetrics, Moir (1956) the editor, quoted Ballantyne's (1902) implication that there have been and were to be few medical men called upon to conduct cases of labour where the products of conception consisted of double monsters. He further quoted what appeared to be a plea by the original author, for every obstetrician to review the literature and to acquaint himself with the ways to overcome the difficulties in delivery of these particular abnormalities.

Thoracopagus is a subdivision of one of the two main groups of symmetrical disomata which may cause extreme dystocia. Each set of twins in this subdivision are almost perfectly formed infants, united more or less completely thorax to thorax or back to back. It is however the only variety of the classification as outlined by Moir which offers any reasonable prospect of partition surgery, salvaging one or both infants.

We have concerned ourselves with a review of the literature to date having had recent experience in the management of one case of thoracopagus, and which we present here for the further reference of other obstetricians and radiologists.

\section{Case history}

On 23 September 1968, a married 30 year-old white woman, who had been attending the gynaecological out-patients because of infertility, reported that she had early presumptive symptoms of pregnancy. Her past history included no full term pregancies, two spontaneous 6 to 8 week abortions and minor pelvic surgery on two occasions.

The patient was not submitted to a vaginal examination as a "Gravindex" test was positive. She was admitted to hospital for a long term rest period to carry her over any " critical period". Her last menstrual period was 16 August 1968 and an estimated date of confinement of 23 May 1969 was given her. She "spotted" at least twice during the early part of her confinement in hospital but from her 19th week of gestation she had no further bleeding episodes. Weekly estriol levels were estimated and only on one occasion in early April 1969 did they give cause for concern. After this, satisfactory levels were maintained.

At 19 weeks the uterus was noted to be 24 weeks in size. The growth of the uterus continued ahead of the period of amenorrhea for the rest of her pregnancy. On 26 March 1969 she was referred to the Radiological department for a maturity estimation and to exclude a twin pregnancy. The examination revealed twins estimated at 30 to 34 weeks gestation. No fetal skeletal abnormalities were observed. From this date on, despite attempts to find two fetal hearts, only one, assumed to be that of the most anterior lying fetus, was heard. As part of a routine investigational survey on pre-diabetes, a

* Now Military Maternity Hospital, Woolwich. 
one hour intravenous glucose tolerance test was carried out on 24 April 1969 and this indicated an overt diabetic state, with a reading of $133 \mathrm{mg}$ per cent at one hour.

On 29 April 1969 contractions were experienced. It was noted clinically, that the lie of the most anterior twin was longitudinal and the presentation was cephalic. The head was situated, resting on the top of the patient's pubic symphysis and distending the suprapubic region. The lie and the presentation of the second and obviously posterior twin could not be made out. Only one fetal heart could be heard. This was regular at 140 beats per minute. An erect lateral X.-ray was taken at that time. Both presentations were confirmed as cephalic, the head of one being described as directed into the pelvis inlet and the other projected anterior to it. Both vertices were at the same level. Within 3 hours the contractions were no longer felt and the preparations made for delivery were abandoned temporarily.

On 14 May 1969 at 0900 hours, an artificial rupture of membranes was performed. The presenting part was confirmed as head and was at a level about $1.5 \mathrm{~cm}$ above the ischial spines. The cervix was almost completely effaced and the os was $2.5 \mathrm{~cm}$ dilated. A small amount of normal-looking liquor was released. The patient was then given a course of buccal oxytocin. Good contractions were experienced five hours after induction and the oxytocin was discontinued. Twenty-four hours after induction the cervix had dilated to $7 \mathrm{~cm}$ but was loosely applied. The presenting part was at the level of the midcavity. The general condition of the patient was good. One fetal heart could be heard and this was regular at 140 beats per minute. The patient was still draining clear liquor. Thirty hours following induction the state of the cervix had not changed and it was decided to perform a caesarean section. A general anaesthetic was given and a transverse lower segment incision made through a much thinned out uterine lower pole. The head of the most anterior fetus was extracted easily through the uterine wound but extreme difficulty was experienced in extracting the fetus further. A rapid exploration detected a tıssue bridge at the sternum, and the diagnosis of conjoined twins was made. It was decided to perform a caesarean section. A general anaesthetic was given and a transverse to an enlargement of the transverse incision by an upward vertical extension. The second attempt was successful and conjoined twins weighing $4994 \mathrm{~g}$ were extracted. They were female. Resuscitation was undertaken and proved successful (Apgar rating 4 at 5 minutes). The third stage was uneventful and the uterine wound was sutured. The uterus contracted and retracted satisfactorily. The abdomen was repaired.

Examination of the placenta showed that it had one umbilical cord. A separate vessel appeared to arise from the placenta and join the only two vessels in the cord. One of the twins had an odd shaped head with a high vault and a skull circumference of $32.5 \mathrm{~cm}$. Its respiratory rate was 60 per minute and there was some recession of its chest. It was joined to its sibling anteriorly, from $2 \mathrm{~cm}$ below its suprasternal notch to a point $1 \mathrm{~cm}$ below the xiphisternum where a common omphalocele of $12 \mathrm{~cm}$ diameter was obvious (Fig. 1). This contained collapsed intestine and liver, the latter organ apparently common to both. The heart rate of both twins was noted to be 136 beats per minute and clinical examination suggested a single common heart.

The twins were placed in an incubator over night and on the 16 May 1969 transferred to the Hospital for Sick Children in London. On admission there, clinical examination and electrocardiography showed no evidence of two electrically independent hearts. Cardiac catheterization and angiography confirmed a single atrium, a 


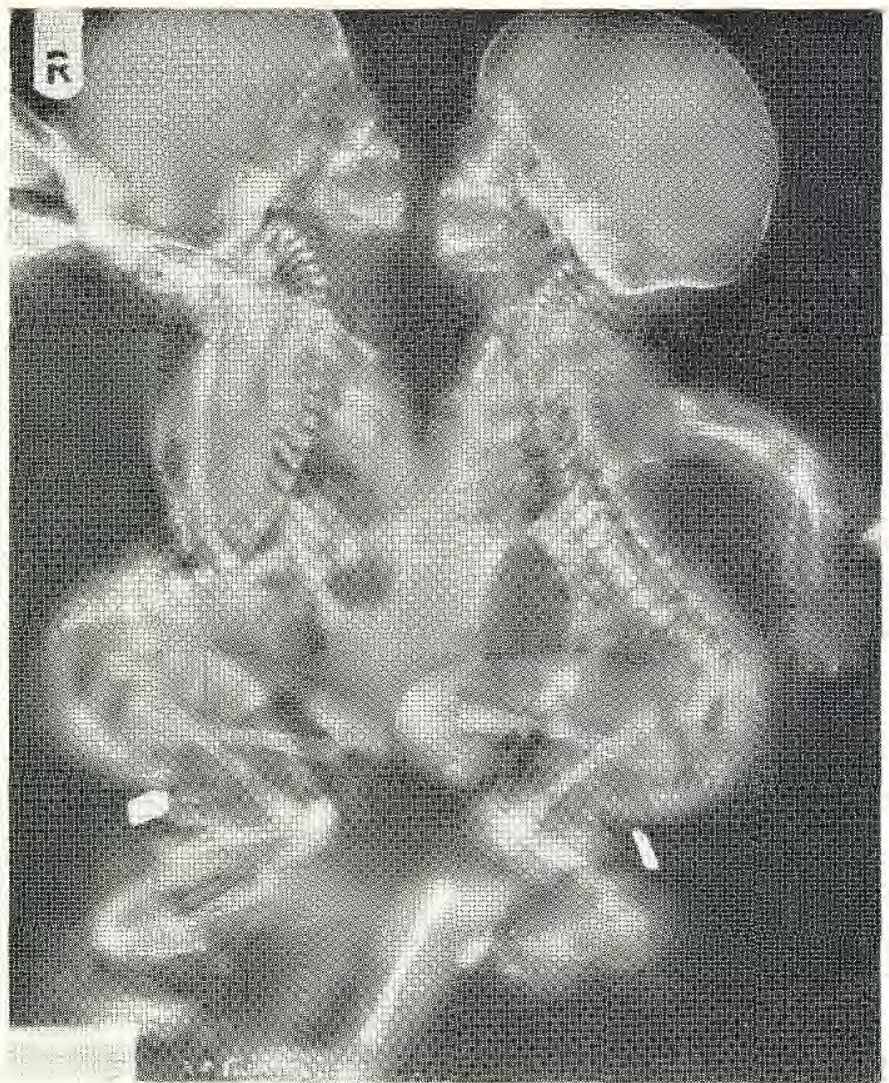

Fig. 1. Roentgenogram demonstrating anterior bridge, from $2 \mathrm{~cm}$ below suprasternal notch to a point $1 \mathrm{~cm}$ below the xiphisternum, and the common omphalocoele.

single ventricle, and separate pulmonary arteries and aortic arches, findings which would have rendered surgical attempts at separation impossible. The twins died on 19 May 1969.

Post mortem confirmed the cardiac catheterization studies. There was distortion of the thoracic cage with a cleft-like space on the right, which had resulted in considerable reduction in the space available for pulmonary development. Both lungs showing a marked degree of hypoplasia. There was some evidence of peritonitis. The gastrointestinal tracts of both twins showed no abnormality. The liver was a fused common organ weighing 150 grams.

\section{Incidence}

We agree with Lu and Lee (1967) that the infrequency of conjoined twins makes it difficult to determine the exact incidence, and we have extracted the two figures of 1 in 6,000 shown by Mudaliar (1930) and 1 in 283,000 of Mortimer and Kirschbaum (1942) from Lu and Lee's and Sarma's (1963) Tables of comparative incidence, as the lower and upper known limits. Thoracopagus appears to be the commonest type of conjoined twins, and this is borne out by Robertson (1953) who quotes a figure of 73 per cent, by Hirst quoted by Mortimer and Kirschbaum (1942) and by Ysander (1924) who 
produce smaller but none the less significant figures of 38.6 and 30.7 per cent respectively. In Lu and Lee's (1967) series four out of five of their cases were of the thoracopagic variety.

Lu and Lee stressed that there was a distinct preponderance of females especially among the thoracopagi, and their figure was 100 per cent. Hill et al (1961) quoted a 3 to 1 ratio and Guttmacher (1962) gave a 70 per cent rating for females as opposed to males.

There also appears to be a predisposition to hydramnois, as experienced by Badawy and Shehata (1961) and Freedman Tafeen and Harris (1962). Although our cases showed no apparent liquor amnii clinically, the first pre-natal radiograph indicated the possibility of the presence of hydramnios.

Diabetes or a history of familial diabetes was found in cases submitted by Badawy and Shehata (1961) and also by Rubinstein and Suidan (1961). An intravenous glucose tolerance test performed at the 35 th week on our own case showed a pre-diabetic state.

\section{Diagnosis}

It must be accepted, that in the past, the diagnosis of thoracopagus has rarely been made until difficulty was experienced in the delivery of what had previously been believed to be, the forecoming and the single twin of a pair. The difficulty has necessitated intrauterine exploration and it has been the exploration that has elicited the diagnosis. Graber (1962) impressed upon his readers that the diagnosis of conjunction, usually made during labour, had only twice before been made prior to labour. He was later supported by Becker (1950). Graber presented a case of thoracopagus, again in which the diagnosis had not been made until the patient had been in labour, but which had been $\mathrm{X}$-rayed in the antepartum period. He admitted that from a retrospective study of the films that there has been several features which would have indicated a diagnosis of conjoined twins. Gray, Nix and Wallace (1950) suspecting a fetal abnormality because of an obvious polyhydramnios undertook radiography in their case. A presumptive diagnosis of thoracopagus was made as a result. The film suggested "something unusual ". The twin pregnancy was apparent. The two heads were lying high at the same level in the fundus, and in the same coronal plane, a position the authors stressed was seldom seen, with normal twins. There was also an unusual degree of hyperextension of the cervical spine. Gray et al indicated that this exaggeration of extension was far too much to allow for the presence of normally developed thoracic cages.

They took a further radiograph after a week of maternal movement and manipulated the fetus manually at the time of the second radiographical study. They could establish no change in the relative positions of the fetuses. They then felt that the diagnosis of conjoined twins could be made with certainty. Gray et al, while admitting that conjoined twins were one of the varieties of obstetrical practice, made a plea for radiological alertness. They reviewed the literature and found one case, that of Klapproth (1942) in which a pre-natal radiographic diagnosis was made. It should be pointed out that this author had described a cephalothoracopagus and the diagnosis might have been more obvious by virtue of the additional cephalic fusion. Gray et al added two further cases of early recognition taken from personal communications from Pendergass and Rhinehart. We have not had the opportunity of studying the last two communications. 
Rohan Williams (1952) stated that when twins are observed on radiography an especial scrutiny of their skeletons should be made for the signs of double monsters. Matthew (1956) also reported a correct pre-natal diagnosis of conjoined twins and when describing his case is noted to have X-rayed his patient at least four times. The earliest radiograph showed a longtitudinal and transverse lie. An extension of both fetal necks was also noted. Matthew's second radiograph showed a close approximation of the thoraces and considerable hyperextension of the necks. His third showed an unchanged relationship between the fetuses and it was this that finally suggested to him the existence of a thoracopagus. A final radiograph made the diagnosis highly probable.

Holland and Bourne (1959) stated that an antenatal diagnosis, presumably by radiography, will bring safety through induction of premature labour or elective caesarean section.

Sarma (1963) in a comprehensive monograph, stated that equal conjoined twins may be diagnosed by antenatal radiography, and his study especially of thoracopagus, paid considerable attention to Graber's criteria in particular. Sarma recognised the pitfalls in diagnosis but gave as classical features of antepartum radiographical diagnosis the following:

a. Both the twins present by the same pole and both will be vertex or both breech. Birnbaum (1912) quoting Veit, stated categorically that "if the first fetus of a twin pregnancy is found lying transversely, the presence of a double monster should be suspected ". Again in the earlier paper by Matthew (1956) an initial X-ray showed a longtitudinal and a transverse lie in a thoracopagus. $\mathrm{Lu}$ and Lee (1967) in their report, demonstrated one of their five cases, with the forecoming twin being cephalic and the lie of the aftercoming twin being transverse. The four remaining cases of $\mathrm{Lu}$ and Lee were breeches, a terata anadidyma, a tranverse lie which resolved to cephalic presentation, and cephalic presentations respectively. From the very nature of the malformation and the lock described later by us, it should follow that the two fetal presenting poles should invariably point in an identical direction, and we cannot but fail to agree with Sarma, that if the poles alter by spontaneous internal version, the disomatous mass will move in toto.

b. The twins face each other. This should be described as the "Kissing position". Graber (1962) however, points out that the approximation may be so great that the twins cannot face each other properly, much less "Kiss" each other.

c. Both heads are at the same level. This is so in the great majority of cases unless the twins are unequal in size, and allowance should be made for slight variations in the levels. A review of the commonest textbooks has revealed diagrams to show the lies of twin pregnancies in general. The diagram shown as (Fig. 2) has been borrowed from Greenhill (1965) (after Guttmacher and Kohl and Portes and Granjon) and the transverse lines $a$ and $a^{\prime}, b$ and $b^{\prime}$ have been drawn in by us to indicate the relative discrepancies in the levels of the presenting parts in the case of twin vertices and the smaller but nevertheless apparent discrepancies between the levels of the presenting parts in twin breeches. From a review of radiographs of twin pregnancies over 3 years at this hospital, it is not very unusual for the fetal heads to lie at the same level. There is in effect in unfused twins, a "sliding mechanism" enabling the presenting pole of the first twin to enter the pelvic brim. In thoracopagus however, the bridge acts as a 


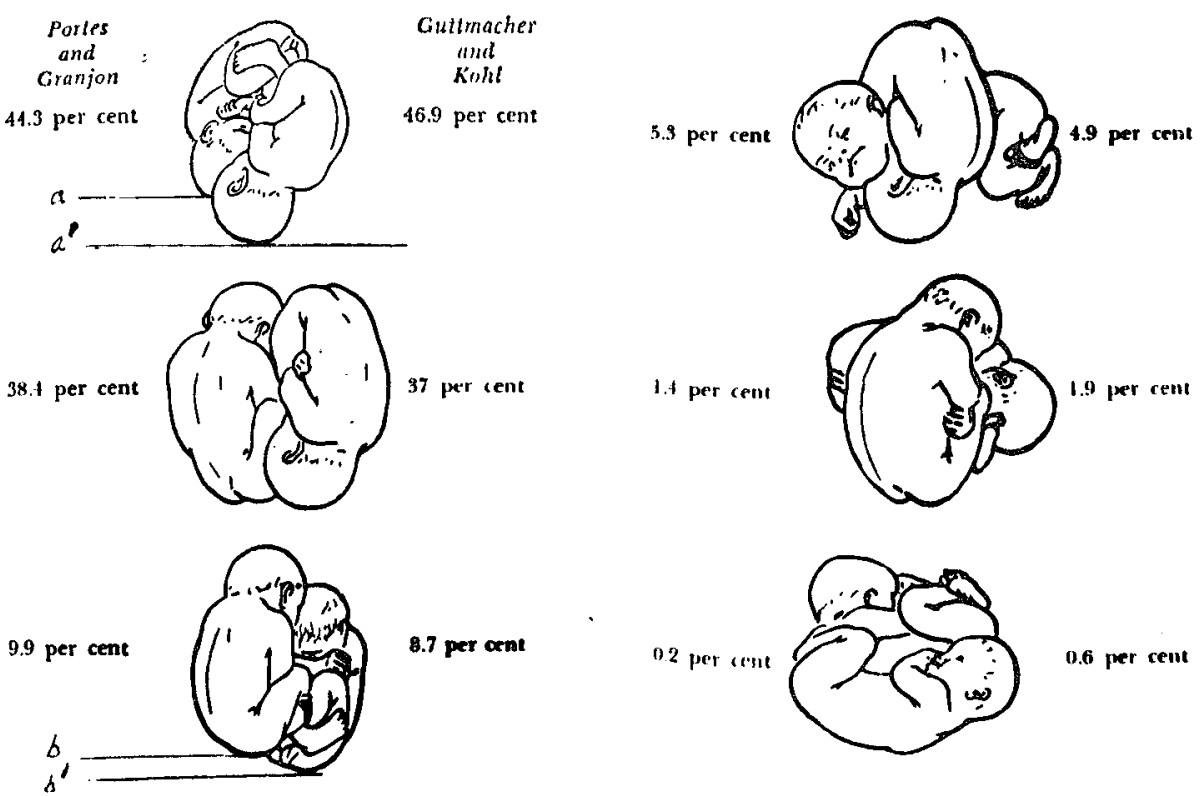

Fig. 2. Diagram borrowed from Greenhill (1965) to indicate relative discrepancies in the levels of presenting parts.

lock, preventing the sliding and the subsequent engagement of the presenting part of the first twin in the pelvic inlet.

d. The thoracic cages of the fetuses are approximated and may be so intimate as to be recognised as fused.

e. There may be unusual hyperextension of the cervical spines, but this varies in degree.

f. Serial radiographs will demonstrate constant interrelationship, and when there is the possibility of conjoined twins, further radiological studies should be made as was done by Matthew (1956).

g. The fetal spines are parallel to each other although there might be slight variations due to the hyperextension.

h. Limb defects may be present.

j. The twins may occupy a single amniotic sac and it was Graber (1962) who observed that the cuddlesome position of the babies probably indicated that a single "cocoon" did in fact allow such a position. Amniography as described below by Melin (1967) proved of utmost value in detecting a single amniotic sac.

k. Soft tissue bridges may be demonstrated by special radiographic techniques. It was apparent that Melin (1967) in the management of his own case was aware of the possibility of the diagnosis of conjoined twins, having $X$-rayed his patient because of polyhydramnios and the gestational size of the uterus. He noted that the twins were facing each other and that there was an abnormal lordosis of the lumbar spines. A repeat X-ray after an interval of two weeks showed that the fetuses had converted to the cephalic presentation with a similar attitude to each other. Amniography was 
performed two days later and this showed a single chorionic and amniotic sac. A 7-hour film taken following a repeat amniography demonstrated a common intestinal tract. Melin was then able to confirm a conjoined twin pregnancy.

\section{Obstetric management}

Looking at the fetal disomatous mass, it invariably appears that it must be impossible for such twins to pass alive and uninjured through the genital canal. Yet, records of the spontaneous live birth of such monsters are found in the obstetric literature, both old and recent. Birnbaum (1912) reports 119 cases of double monsters of which 62 per cent were delivered spontaneously. He stated also that the chance of a vaginal delivery is much better with breech presentation (which is relatively more frequent) and also, better when the fetuses are dead and the union more pliable.

$\mathrm{Lu}$ and Lee (1967) stated that the vaginal delivery of double monsters may at times present no difficulty as such pregnancies rarely go to term, and the conjoined fetuses may not in fact exceed the size of a normal singleton. They warned however, that the presence of a fully formed double monster, created an obstetric problem if it was not recognised until labour was obstructed. They quoted Mahfouz (1949) who indicated that most accidents would occur from forcible and hasty attempts at extraction presumably at late discovery.

It has been stressed that if the diagnosis can be made radiologically early on in pregnancy then the pregnancy should be terminated by rupturing the membranes artificially. Again if a radiological diagnosis is made late in pregnancy, and it is considered that there might be some disproportion in labour, then the obstetrician should resort to caesarean section. It was Franklin (1964) who stated that pre-natal radiological diagnosis was possible and should influence the choice of delivery.

Destructive operations have given place to caesarean section mainly for the following reasons:

a. It may be considered a relatively safe procedure particularly through a classical incision: Badawy and Shehata (1961).

b. There are instances of conjoined twins who have survived happily for many years.

c. The most important reason is that in some cases, conjoined twins may not now be condemned to a full-time co-existence. So great have been the advances in surgery that successful separation has been possible in selected cases. Ballantyne (1902) stated that if conjoined twins of the thoracopagic variety could be extracted alive from the uterus, they not uncommonly, survive their birth. He talked of the advances of modern surgery at that time and the renewed efforts which have been made in the years recent to his report to separate cases of conjoined twins. He felt that the results had been encouraging, but admitted that they were not outstanding. It is thought that he may have been referring, in particular, to Doyen's successful operation on the Radica-Doodica sisters which had survived their birth, and only underwent separation operation some years later because one had developed active tuberculosis. This is reputed to have been the first successful separation has been possible in selected cases. Ballantyne (1902) stated that if that radiography and improved technique for controlling haemorrhage e.g. from the liver, would doubtless enable the surgeons of the future to select the proper cases for separation. 
The following authors have all reported additional surgical successes for all types of conjoined twins: Scammon (1925), Holm (1936), Grossman et al (1953), Reitmann, Smith and Geller (1953), MaLaren (1936), Aird (1954), Spencer (1956), Wilson and Storer (1957), Peterson and Hill (1960), Koop (1961 and O'Connell (1964). At the time of Wilson and Storer's paper only nine instances of separated conjoined twins in which both have survived had been reported.

Aird (1954) quoted what he believed was the first successful operation performed presumably shortly after birth, by an R.A.M.C. officer in a Military Families Hospital at Portsmouth in 1912, one twin of which was in fact alive and well at the time of the Aird's paper 41 years later, the other one succumbing to pneumonia 4 months following the separation.

Ligat (1912) reported a 14 pound (6363 g) thoracopagus delivered by caesarean section, and the following authors also gave favourable reports of delivery by this method: Matthew (1956), Freedman, Tafeen and Harris (1962), Guttmacher (1962), Solomons (1962) and Kreutner, Levine and Thiede (1963).

In the publication by $\mathrm{Lu}$ and Lee (1967) two cases of thoracopagus twins were delivered per vaginam without destructive operations being performed. The first set of twins weighed only $2300 \mathrm{~g}$ and the second set weighed $2250 \mathrm{~g}$. In another of their cases the twins underwent a destructive operation before vaginal delivery. They weighed $4350 \mathrm{~g}$. The last 2 cases were delivered by lower segment caesarean section and weighed $2700 \mathrm{~g}$ and $4500 \mathrm{~g}$ respectively.

As to the type of caesarean section, it is stressed that if the operator is certain that he will experience difficulty in extracting the disomatous mass through a lower segment incision, then he should resort to the classical approach. Badawy and Shehata (1961) encountered such difficulty and favoured the classical incision. Lu and Lee (1967) delivered at least two of their cases through a lower segment incision and mention no difficulty whatsoever. One of us (B.G.) experienced temporary difficulty in extracting the twins through a lower segment and considered himself fortunate that no lacerations had been caused. In retrospect he felt that on any future occasion the classical incision would be his choice. Ligat (1912) does not describe his method of section, but it is felt that it must have been a classical one, for the history of the lower segment procedure, certainly in Britain, appears to date from 1911, Munro Kerr being one of its main exponents and for many years a "lonely voice" ".

Moir (1956) states that delivery should be by caesarean section but indicates in no way the choice of incision. Graber (1962) was of the opinion that caesarean section was not warranted even if the antepartum diagnosis of thoracopagus had been made, on the grounds that if one anomaly existed then there were usually others. He suggested that if the union was a simple skin bridge, there would be sufficient elasticity to allow the babies to deliver spontaneously. This is certainly not the view held by us. Graber's prediction that the hazard to the mother would be less if vaginal embryotomy is performed rather than caesarean section is considered far from the truth. A classical section would afford more than adequate exposure for a destructive operation and thus obviate the need for what would amount to a blind fumbling via the vagina, and would be far less hazardous to the patient.

Matthew (1956) performed a classical caesarean section at the 35 th week for his case of thoracopagus and delivered the conjoined twins intact through what he described 
as an adequate incision. He thus gives support not only to what he believed was the correct obstetric management but also to an incision which allows fairly full exposure, should embryotomy become necessary.

Having successfully diagnosed his case Melin (1967) most recently was left with making a firm decision as to the method of delivery. It appears that he was prepared to give strong support to vaginal delivery and felt secure in the knowledge that blood was available and caesarean section was practical at a moment's notice. The patient apparently made the decision for him when she started into spontaneous labour some 48 hours after the repeat amniography. Delivery was effected vaginally experiencing only moderate difficulty with the first twin and extreme difficulty with the second. The combined weight was $4,110 \mathrm{~g}$. Melin was the only author who indicated that a pediatrician and a surgeon were in readiness should there have been a chance of the infants' survival.

\section{Summary and conclusion}

A case of conjoined twins has been presented and the incidence, diagnosis and obstetric management has been discussed. Any conclusion to be drawn must concern firstly, the diagnosis of the case presented, and secondly the obstetric management. In retrospect, the original radiograph showed that the fetal heads were projected over the sacrum overlapping in the sagittal plane. That the vertex of one appeared slightly inferior to that of the other was in most part due to projection. The most notable feature was the extension of both heads and extension of the lumbar spine of the twin lying on the right side (Fig. 3). No fetal abnormalities were observed and a degree of polyhydramnios was evident. The second radiograph (Fig. 4) requested primarily for an assessment of the AP pelvic diameters showed the head of one twin directed into the pelvic brim in an occipito-posterior position with the second head lying anterior to it and projected over the pubis. The vertices were at the same level. There was some axial rotation of the anterior head, obliquity of the cervical and upper dorsal spines and of the visualised upper rib cage.

The most valuable antenatal finding was the abnormal attitudes of the fetal spines. This was combined with presentation by the same pole at the same level. The twins did not face one another and the lateral view indicated that the bridge allowed some axial rotation, at least of the upper trunk, neck and head.

A postnatal $\mathrm{X}$-ray revealed for the first time the obvious soft tissue bridge extending from the sternal angle to the lower abdominal walls. Superiorly there was a bony bridge believed to represent the manubrium sterni. The twin lying to the left had one attenuated clavicle.

It is emphasised that a high degree of awareness is necessary to make the antenatal diagnosis of conjoined twins. The importance of abnormal attitudes of the fetal spines has been stressed repeatedly by all authors and should alert the observer to the possibility of fetal abnormality. Obstetric management of all cases over 35 weeks gestation should be by caesarean section and at the same time thought should be given to the classical approach. Much consideration should be given as to the advisability of induction of labour prior to 35 weeks following a radiological diagnosis of conjouning, and we are of the opinion that the pregnancy can be encouraged to go to near term in the hope that there might be a possibility of separation with the ultimate survival of one or both twins. A spontaneous onset of premature labour before 35 weeks should present only the 


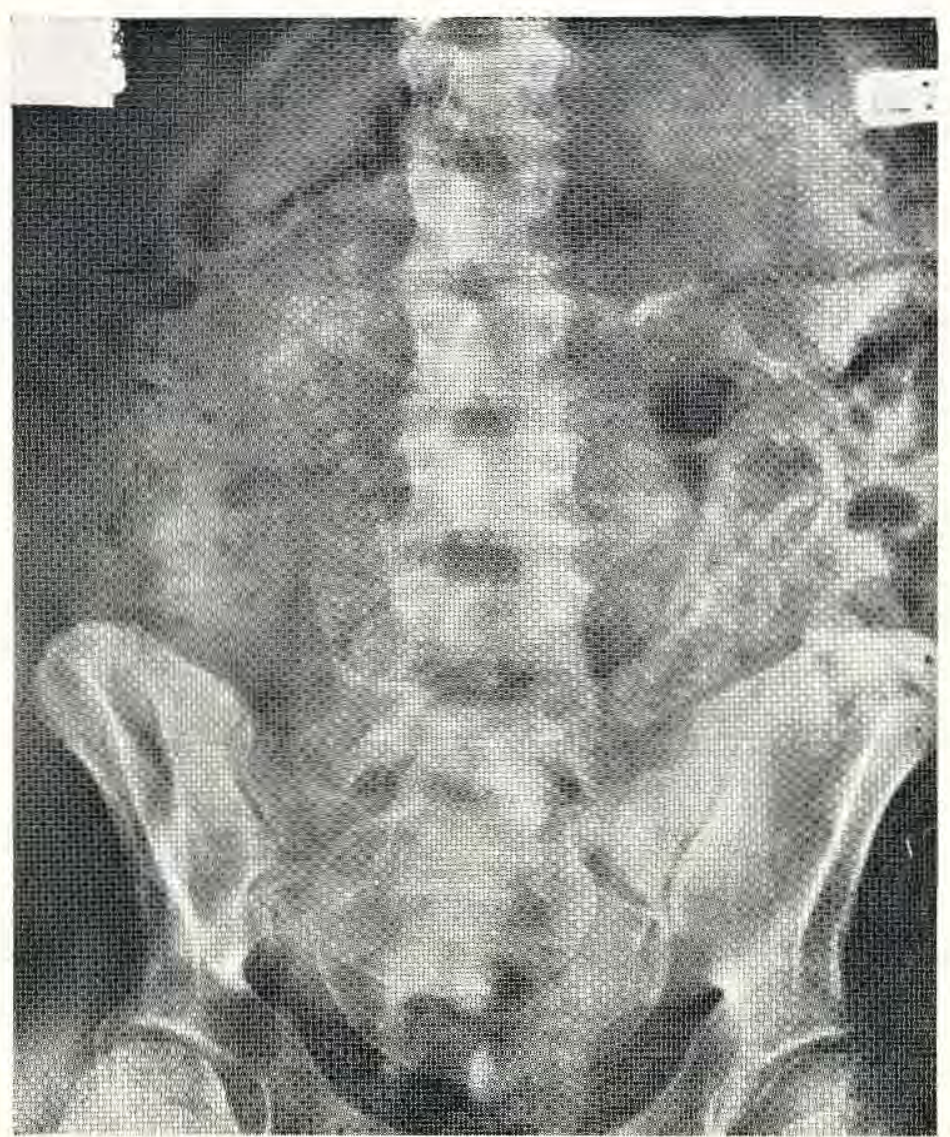

Fig. 3. Original radiogram with fetal heads projected on the sacrum and cxtension of the spines particularly of that on the right.

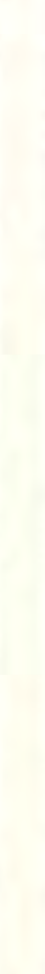

(1)

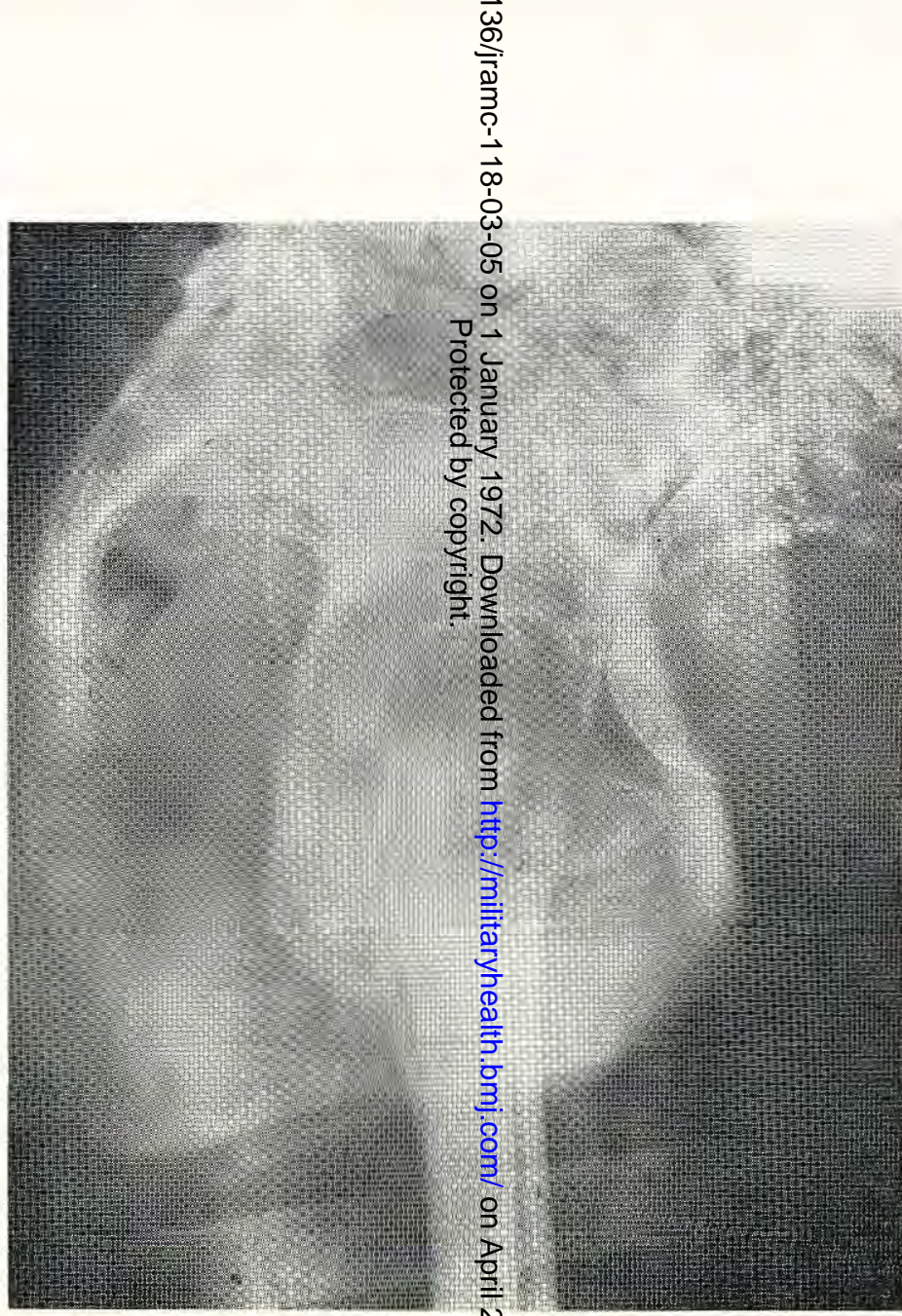

Fig. 4. The head of one twin is dircctoll into the minor pelvis in occipulposterior position with the second heandanterior and over the pubis.

$$
\begin{aligned}
& \text { N } \\
& \omega \\
& 0 \\
& 0 \\
& 0 \\
& \stackrel{0}{D} \\
& \stackrel{D}{్}
\end{aligned}
$$


problem of the method of delivery and if a vaginal " extraction" is contemplated, this should be performed in an operating room with a team in readiness for caesarean section.

\section{Acknowledgements}

We wish to express our thanks to, Colonel R. G. MacFarlane, M.B.E., Commanding Officer, British Military Hospital, Iserlohn for permission to publish this paper, and to Professor A. W. Wilkinson of the Hospital for Sick Children, Great Ormond Street, London, for his help and advice.

\section{REFERENCES}

AIRD, K. (1954). Brit. med. J. i, 831.

BADAWY, A. H, and ShehatA, R. (1961). Obstet. and Gynec 18, 106.

Ballantyne, J. W. (1902). Manual of Antenatal Pathology and Hygiene. William Green. Edinburgh. P. 636.

BECKER, F. (1950). Zbl. Gynak. 72, 510.

Birnbaum, R. (1912). Congenital Diseases and Malformations of the Fetus. J. \& A. Churchill. London. Franklin, A. W. (1964). Brit. med. J. i, 1342.

Freedman, H. L., Tafeen, C. H. and Harris, H. (1962). Amer. J. Obstet. Gynec. 84, 1904.

Graber, E. A. (1962). Amer. J. Obstet. Gynec. 84, 1908.

Gray, C. M., Nix, H. G. and Wallace, A. J. (1950). Radiology 54, 398.

Greenhili, J. P. (1965), Obstet1ics. 13th ed. Saunders. Philadelphia. P.625.

Grossman, H. J., Sugar, O., Greeley, P. W. and Sadove, M. S. (1953). J. Amer. med. Ass. $153,201$.

GutTmacher, A. F. (1962). Amer. J. Obstet. Gynec. 84, 1908.

Hill, A. J., Peterson, C. G., Grondahl, R. D. and Krippaehne, W. W. (1961). J. Pediat. $58,99$.

Holland, E. and Bourne, A. (1959). British Obstetric and Gynaecological Practice. 2nd ed. William Heinemann. London. P. 777.

Holm, H. H. (1936). Minn. Med. 19, 740.

KLAPPROTH, H. (1942). Radiog. and Clin. Photog. 18, 70.

Koop, C. E. (1961). Surgery 49, 271.

Kreutner, A. K., Levine, J. and Thiede. (1963). New Engl. J. Med. 268, 1388.

LigAT, D. (1912). J. Obstet. Gyneac, Brit. Emp. 21, 295.

LU, T. and LEE, K. H. (1967). J. Obstet. Gynaec. Brit. Cwlth 74, 757.

Mahfouz, N. P. (1949). Atlas of Mahfouz's Obstetrical and Gynaecological Museum, Sherratt, Altrincham, Vol. 3. P. 1168.

MatThew, D. G. (1956). J. Obstet. Gynaec. Brit. Emp. 63, 226.

Mclaren, D. W. (1936). Brit. med. J. ii, 971.

MELIN, J. R. (1967). Obstet. and Gynec. 29, 50.

MoIR, J. C. (1956). Munro Kerr's Operative Obstetrics. 6th ed. Bailliere, Tindall \& Cox. London. P. 253.

Mortimer, B. and Kirschbaum, J. D. (1942). Amer. J. Dis. Child. 64, 697.

Mudaliar, A. L. (1930). J. Obstet. Gynaec. Brit. Emp. 37, 753.

O'Connell, J. E. A. (1964). Brit. med. J. i, 1333.

Peterson, C. G. and Hill, A. J. (1960). Ann. Surg. 152, 717.

ReitmanN, H., Smith, E. and Geller, J. S. (1953). J. Amer. med. Ass. 153, 1360.

Rohan Williams, E. (1952). A Textbook of X-ray Diagnosis. 2nd ed. Saunders. Philadelphia. P. 574.

Robertson, E, G. (1953). Arch. Neurol. Psychiat. (Chic.) 70, 189.

RubinsteIn, R. I. and SUIDAN, F. G. (1961). Amer. J. Obstet. Gynec. 82, 325.

SARMA, V. (1963). Mediscope 6, 479.

Scammon, R. E. (1925). Foetal Malformation. Col. 6 of Pediatrics. Ed. by I. A. Abt. Philadelphia.

Scammon, R. E. (1926). In. Abstr. Internat. Ass. Pediatrics. Philadelphia.

Shaw, C. C., Brumbaugh, B. B. and Novey, M. A. (1934). Amer. J. Obstet. Gynec. 27, 655.

Solomons, E. (1962). Amer. J. Obstet. Gynec. 84, 1908.

SPENCER, R. (1956). Surgery. 39, 827.

Wilson, H. and Storer, E. H. (1957). Ann Surg. 145, 718.

YsANDER, F. (1924). Human Thoracopagic Monsters. Uppsala. 